\title{
Son Preference, Childbearing Behavior and Respondent Socio-Demographic Characteristics in Morogoro, Tanzania
}

\section{Jaha Mulema}

Assistant Lecturer, Geography, Muslim University of Morogoro, TANZANIA

\begin{abstract}
The study finds out how son preference influences childbearing behavior in the Morogoro municipality, Tanzania. The study was conducted at six wards in the Morogoro municipality. A total of 203 households was surveyed. Purposive and simple random sampling was adopted to select households to be included in the study. A chi-square test was performed to test for the association between son preference and family size. Quantitative analysis of parity progression ratio and sex ratio at last birth shows that couples' preference for sons adjust childbearing upwards in the Morogoro municipality. The findings show that couples' continue having children until they reached the desired number of sons. The study concluded that son preference was a factor toward high childbearing behavior in the Morogoro municipality.
\end{abstract}

Keywords: Son preference, sex preference, childbearing behavior, Morogoro, Tanzania

\section{INTRODUCTION}

Several studies show son preference has substantial influence on childbearing behavior in Asia due to strong son preference existing in those countries (Leone, 2003; Shirazi, 2004;). For example, in Saudi Arabia, Khraif (2001) observes that, childbearing was lower for women's who have a large proportion of male children. On supporting this, Shirazi (2004) indicates that, childbearing behavior in Pakistan was attributed to the desire on parts of parents to ensure a certain number of living sons. Likewise, in Northern India women's having more daughters desired larger number of children in comparison to those who have an equal number of sons and daughters. Furthermore, women's with more number of sons or only one son desired a small number of children (Dhilon and Sing, 2010).

So far, several studies were conducted to examine the influence of son preference on childbearing behavior in Africa. However, based on cross-national studies which use data from Demographic and Health Survey (DHS) it was observed that, the effect of son preference on childbearing behavior was essentially nonexistent in Sub-Saharan Africa (Bongaarts, 1998; Fuse, 2008).

Contrary to that, some studies suggest that son preference influence childbearing behavior in Sub-Saharan Africa. For example, Dibaba (2008) found that, number of living sons and daughters were associated with the women decisions to stop childbearing in Ethiopia. This 
was supported by Kiriti and Tisdell (2005) who indicated that, son preference may lead parents to have many children in search for sons in Kenya.

Based on different findings, in sub-Saharan Africa, it is important to establish a relationship between son preference and childbearing behavior in Tanzania. So far, there is no study that had been conducted to examine the influence of son preference on childbearing behavior in Tanzania, and the Morogoro municipality in particular. What becomes more interesting is to see how son preference influences childbearing behavior and whether the influence of son preference on childbearing behavior differs between respondent with different sociodemographic characteristics.

\section{Materials AND Methods}

\section{The Study Area}

This study was carried out in the Morogoro municipality in Morogoro region. Morogoro is the region located in the Eastern zone of Tanzania and is bordered by seven regions, namely; Coast region and Lindi in the east, Manyara and Tanga in the north, Dodoma and Iringa in the west and Ruvuma in the south. The region has five districts namely; Kilombero, Ulanga, Mvomero, Kilosa and Morogoro. Administratively, the Morogoro municipality is divided into twenty nine wards.

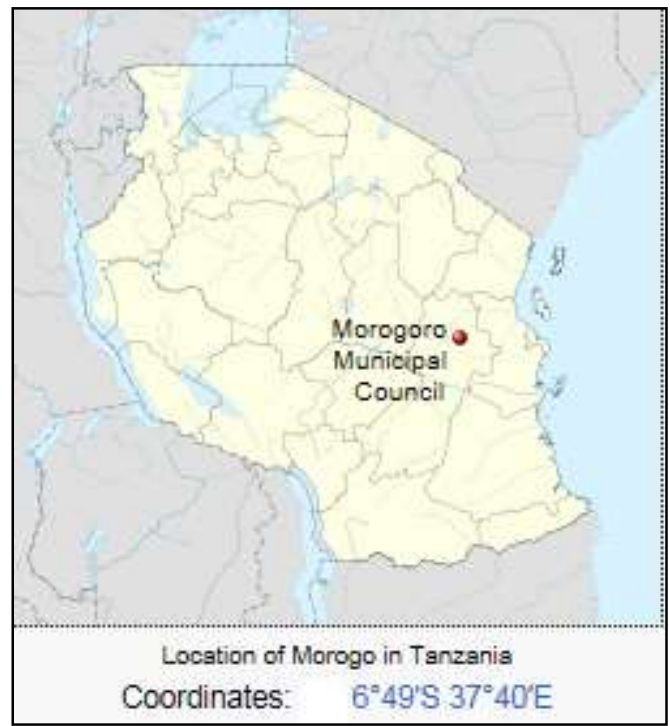

Source: http:/ /en.wikipedia.org/wiki/Morogoro

\section{Data}

In this study self administered questionnaire was used to collect data from the selected households. In this study a sample of 203 households in the Morogoro municipality was included in the survey, whereby one member from each household was surveyed. Data on the sequence of the birth for the past cumulative fertility of the women in the household surveyed were collected. These data were used to determine two behaviors; childbearing stopping behavior and childbearing continuing behavior. 


\section{Results AND Discussions}

This study found that, parents in the Morogoro municipality were influenced by son preference in stopping childbearing after reaching the desired number of sons or continuing childbearing when the desired number of sons is not reached.

\section{The Influence of Son Preference on Childbearing Stopping Behavior}

The study uses sex ratio at last birth to determine the influence of son preference in childbearing stopping behavior. The influence of son preference on childbearing stopping behavior was shown by the proportion of the women's whose last child was a boy to be higher than those whose last child was a girl.

On the wards selected the proportion of women's who stopped childbearing whose last child was the boy was higher (57.6\%) than that of women's whose last child was a girl $(42.4 \%)$. A close examination from the above findings shows that, the parents in household surveyed influenced by son preference to stop childbearing hence, increase the number of children they bear when the desired number of sons was not reached. There association between wards and childbearing stopping behavior shows the value of $X^{2}=3.0, p$-value $=0.695$.

In connection with marital status, the proportion of women's who stopped childbearing, whose last child was a boy was higher among those who were separated $(66.7 \%)$, followed by those who were divorced $(60 \%)$ and those who were married (58\%). In contrary, it was lower for those who were widowed (46.7\%). On average for all marital status, the proportion of couples who stop childbearing whose last child was a boy was higher $(57.6 \%)$ than those whose last child was a girl (42.4\%). Regarding religion of the respondent, the proportion of women's who stopped childbearing whose last child was a boy was higher among those with other religions (66.7\%) followed by Muslims (64.9\%), Catholics (52.9\%) and Protestants $(52.7 \%)$. On average, for all religion, the proportion of couples who stop childbearing whose last child was a boy was higher (57.6\%) than those whose last child was a girl (42.4\%). These results suggest that childbearing stopping behavior was strongly driven by son preference in all religions with $X^{2}=2.9, p$-value $=0.401$. In terms of educational status, the proportion of women's who stopped childbearing whose last child was a boy was higher among the respondent with other kind of education (100\%) followed by those with undergraduate education $(63.4 \%)$, secondary education $(60.8 \%)$, diploma or certificates $(56.7 \%)$ and primary education (55.6\%). In contrary, the proportion of couples who stopped childbearing whose last child was a boy was lower among those with postgraduate education (25\%) than those whose last child was a girl. In average, for all educational levels, the proportion of couples who stop childbearing whose last child was a boy was higher $(57.6 \%)$ than those whose last child was a girl $(42.4 \%)$. This result suggests childbearing stopping behavior was strongly driven by son preference in four age groups with $X^{2}=6.9, p$-value $=0.584$.

In terms of occupation of the respondent, the proportion of women's who stopped childbearing whose last child was a boy was higher among mixed farmers $(90.9 \%)$, followed by those who engaged in other activities (80\%), artisan (66.7\%), employed workers (56.9\%), farming (51.4\%) and business (51.4\%). Pastorals have the same proportion of couples who stopped childbearing whose last child was a boy and those whose last child was a girl (50\%). On average, for all economic activities the proportion of couples who stop childbearing whose last child was a boy was higher (57.6\%) than those whose last child was a girl (42.4\%). Looking closer at these relationships, suggests childbearing stopping behavior was strongly driven by son preference with $X^{2}=7.6, p$-value $=0.270$. 


\section{The Influence of Son Preference on Childbearing Continuing Behavior}

In order to examine the influence of son preference on couples' intention to continue childbearing parity progression ratio was calculated. Since the average number of children ever born (CEB) by women in the study area was 4.6 children, then this study examine the progression ratio from fourth birth to fifth birth referred as parity four and parity five thereafter. Progression to parity five was specifically selected to examine how son preference influences continuing childbearing after couples reaching the average fertility of the Morogoro municipality. The influence of son preference in childbearing continuing behavior was shown by proportion of those whose fourth child was a girl and continue to parity five was higher than those whose fourth child was a boy, while the influence of daughter preference was shown from those whose last child was a boy and continue to parity five was higher than those whose fourth child was a girl.

On the wards selected women's whose fourth child was a girl was more likely to continue to parity five $(56.8 \%)$, than those whose fourth child was a boy (43.2\%). A close examination of above findings indicates that couples continue childbearing when they didn't reach their desired number of sons with $X^{2}=2.5, p$-value $=0.783$. With regards to marital status, the result shows that the proportion of couples whose fourth child were a girl and progress to parity five were higher among widow $(66.7 \%)$ followed by those who were married $(56.9 \%)$. On the other hand the probability of progressing to parity five was equal to those who were divorced (50\%) and lower among those who were separated (33.3\%). In average for all marital status couples whose fourth child was a girl was more likely to progress to parity five $(56.8 \%)$ than couples whose fourth child were a boy $(43.2 \%)$. It would be worth mentioning at this juncture that, continuation of childbearing to parity five was also driven by son preference. The trend that probability of continuing childbearing regarding marital status has $X^{2}=1.1$ with $p$-value $=0.776$.

In connection to religion of the respondents, the proportion of couples whose fourth child was a girl and continue to parity five were higher among Catholics (70\%) followed by protestants (65\%). This proportion was lower among Muslims (41.7\%) and it was equal among those with other religions $(50 \%)$. On average for all religions couples whose fourth child was a girl was more likely to progress to parity five $(56.8 \%)$ than couples whose fourth child were a boy $(43.2 \%)$. This result suggests that continuation of childbearing to parity five was strongly driven by son preference with $X^{2}=6.1, p$-value $=0.108$. A close look at this pattern shows that Muslims have lower son preference than other religions. This result seems to be collaborated by Mutharayappaet al., (1997) in their study on son preference and its effect on fertility in India, found that the effect of son preference was weaker among Muslims than among Hindus when we consider the parity progression of women with two surviving children.

With respect to levels of education, the proportion of couples whose fourth child was a girl and continue to parity five were higher among those with secondary education (71.9\%) followed by those with undergraduate education (53.8\%) and those with primary education (52\%). This proportion was lower among those with postgraduate education (33.3\%) followed by those with a diploma or certificates $(40 \%)$. On average, for all levels of education, couples whose fourth child was a girl was more likely to progress to parity five $(56.8 \%)$ than couples whose fourth child were a boy $(43.2 \%)$. This result suggests that continuation of childbearing to parity five was strongly driven by son preference with $X^{2}=5.6, p$-value $=0.277$.

A close examination of these results suggests that, those with postgraduate education were less likely to be influenced by son preference. Their result in parity progression shows less influence of son preference on their family size; hence researcher sees that, higher levels of education lead to reduction in son preference. This was consistent with the work of Mutharayappaet al., (1997) who found that among women with two surviving children, parity progression was lower among literate women than among illiterate women. With respect to the occupation of the respondent, the proportion of couples whose fourth child was a girl and continue to parity five were higher 
among those who engaged in business (76.5\%), followed by artisan (60\%), mixed farmers (60\%) and employed workers (52\%). On the other hand, pastorals' probability to progress to parity five was equal to those couples with a fourth child who was a boy or a girl (50\%). On average, for all livelihood promotion activities couples whose fourth child was a girl was more likely to progress to parity five (56.8\%) than couples whose fourth child were a boy $(43.2 \%)$. Looking closer at these relationships, suggests that the probability to continue childbearing to parity five was driven by son preference with $\mathrm{X}^{2}=3.8, p$-value $=0.586$.

\section{CONCLUSION}

This study found that the existing son preference affects childbearing stopping behavior because, couples continue childbearing until they reach the desired number of sons and then they stop childbearing at that point. On average the proportion of couples who stop childbearing whose last child was a boy was higher (57.6\%) than those whose last child was a girl (42.4\%). This result suggests that most couples continue having children until they get a son and then they stop childbearing, hence influencing the number of children born. The findings from the parity progression ratio from parity four to parity five reveal that, couples whose fourth child was a girl was more likely to progress to parity five (56.8\%) than couples whose fourth child was the boy $(43.2 \%)$. This result suggests continuation of childbearing behavior to parity five was strongly driven by a desire to have sons, hence increasing the number of children they bear when the number of desired sons was not reached.

\section{REFERENCES}

Bongaarts, J. (1998). Fertility and Reproductive Preferences in Post-Transitional Societies. Paper Prepared for the conference on Global Fertility Transition, Bellagio, Italy. [Online] Available: http:/ / www.popcouncil.org/pdfs/wp/114.pdf (May, 25, 2013).

Dhilon, P., and Sing, L. L. (2010). Time Varying and Unvarying Factors Affecting Ideal and Actual Family Size in North India. [Online] Available: http:/ / paa2010.princeton.edu/download.aspx?submissionId=101274 (September, 13, 2013)

Dibaba, Y. (2008). Factors Influencing Women's Intention to Limit Childbearing in Oromia, Ethiopia. Journal of Health Development, 22, 28-33.

Fuse, K. (2008). Gender Preferences for Children: A multi country study. [Online] Available: http:/ / etd.ohiolink.edu/send-pdf.cgi/Fuse\%20Kana.pdf (October, 10, 2013).

Khraif, M. R. (2001). Fertility in Saudi Arabia: Levels and Determinant. A Paper Presented at XXIV General Population Conference, Salvador, Brazil, [Online] Available: http://www.iussp.org/Brazil2001/s60/S62_03_khraif.pdf (May, 25, 2013).

Kiriti, T. W. and Tisdell, C. (2005). Family Size, Economics, and Child Gender Preference: A Case Study in the Nyeri District, Kenya. [Online] Available: https://editorialexpress.com/cgibin/conference/download (October, 7, 2013).

Leone, T., Mathews, Z., \&Zuanna, G. D. (2003). Impact and Determinants of Sex Preference in Nepal. International Family Planning Perspectives, 29, 69-75. [Online] Available: http:/ / www.guttmacher.org/pubs/journals /2906903.pdf (October, 12, 2013).

Mutharayappa, R et al., (1997). Son Preference and Its Effects on Fertility in India. National Family Health Survey Subject Reports, No. 3. [Online] Available: http://www2.eastwestcenter.org/pop/misc/subj-3.pdf (February, 12, 2013).

Shirazi, S. A. (2004). Gender Preference: A Determinant of Family size in Lahore- Pakistan. [Online] Available: http:/ / paa2004.princeton.edu/download.asp?submissionId (September, 13, 2013). 
Publish Online and Print Version Both

ISSN Online: 2312-203X 